\title{
Silencing of STIM1 attenuates hypoxia-induced PASMCs proliferation via inhibition of the $\mathrm{SOC} / \mathrm{Ca}^{2+} / \mathrm{NFAT}$ pathway
}

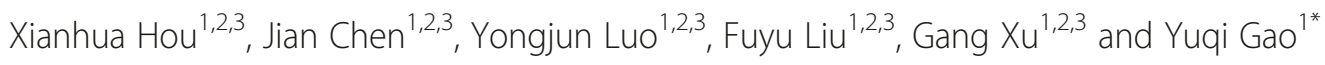

\begin{abstract}
Background: Stromal interaction molecule 1 (STIM1) is a newly discovered $\mathrm{Ca}^{2+}$ sensor on the endoplasmic reticulum which is an indispensable part in the activation of store-operated $\mathrm{Ca}^{2+}$ channels (SOC). Recent studies demonstrate that SOC of pulmonary smooth muscle cells (PASMCs) were upregulated by chronic hypoxia which contribute to the enhanced pulmonary vasoconstriction and vascular remodeling. However, the exact role of STIM1 in the development of chronic hypoxic pulmonary hypertension(HPH) remains unclear.
\end{abstract}

Methods: In this study we investigated the cellular distribution and expression of STIM1 by immunofluorescence, qRTPCR and Western blotting methods in Wistar rat distal intrapulmonary arteries under normal and chronic hypobaric hypoxic conditions. In vitro, Wistar rat PASMCs were isolated and cultured. PASMCs were transfected with siRNA targeting STIM1 gene by liposome. The expression of STIM1 protein was detected by Western blotting. $\left[{ }^{3} \mathrm{H}\right]$-thymidine $\left.\left({ }^{3} \mathrm{H}\right]-\mathrm{TdR}\right)$ incorporation were performed to detect PASMCs proliferation. The cell cycle was analyzed by flow cytometry. The SOC-mediated $\mathrm{Ca}^{2+}$ influx was calculated by $\mathrm{Ca}^{2+}$ fluorescence imaging and the nuclear translocation of NFATC3 was determined by immunofluorescence and Western blot analysis of nuclear extracts.

Results: We found that during the development of HPH and the initiation of vascular remodeling, the mRNA and protein expression levels of STIM1 significantly increased in the distal intrapulmonary arteries. Moderate hypoxia significantly promotes PASMCs proliferation and cell cycle progression. Silencing of STIM1 significantly decreased cellular proliferation and delayed the cell cycle progression induced by hypoxia. Silencing of STIM1 also significantly decreased SOC-mediated $\mathrm{Ca}^{2+}$ influx and inhibited the nuclear translocation of NFATC3 in hypoxic PASMCs.

Conclusion: Our findings suggest that chronic hypobaric hypoxia upregulates the expression of STIM1 in the distal intrapulmonary arteries which plays an important role in the hypoxia-induced PASMCs proliferation via $\mathrm{SOC} / \mathrm{Ca}^{2+} / \mathrm{NFAT}$ pathway and may represent a novel therapeutic target for the prevention of hypoxia pulmonary hypertension.

Keywords: Stromal interaction molecule 1, RNA interference, Pulmonary hypertension, Hypoxia, Cell proliferation

\section{Background}

Chronic exposure to hypobaric hypoxia cause hypoxic pulmonary hypertension (HPH), which is characterized by pulmonary vasoconstriction (HPV) and vascular remodeling [1]. The relationship between $\mathrm{Ca}^{2+}$ and $\mathrm{HPH}$ has been throughly investigated. Hypoxia inhibits the Kv channels, leading to cell membrane depolarization, and

\footnotetext{
*Correspondence: gaoy66@yahoo.com

'Department of Pathophysiology and high altitude physiology, College of high altitude military medicine, Third Military Medical University, Chongqing, China

Full list of author information is available at the end of the article
}

triggers $\mathrm{Ca}^{2+}$ influx from the L-type $\mathrm{Ca}^{2+}$ channels. The increased $\mathrm{Ca}^{2+}$ levels cause pulmonary arterial smooth muscle cells (PASMCs) to constrict and proliferate which contributes to the development of pulmonary hypertension [2-5]. However, recent studies suggested that the store-operated $\mathrm{Ca}^{2+}$ channel (SOC) in addition to L-type $\mathrm{Ca}^{2+}$ channels are also involved in chronic hypoxic pulmonary hypertension [6]. The activation of SOC is triggered by a reduction in the concentration of $\mathrm{SR} \mathrm{Ca}^{2+}$, which can be depleted by inhibiting sarcoendoplasmic reticulum $\mathrm{Ca}^{2+}$ ATPases with thapsigargin (TG)

\section{Biomed Central}


$[7,8]$. Recently, an RNAi-based screening approach revealed that a novel membrane-spanning protein, stromal interaction molecule 1 (STIM1), was required for the activation of SOC $[9,10]$. STIM1 is a $90-\mathrm{kDa}$ type-I transmembrane $\mathrm{Ca}^{2+}$-binding protein with a luminal helixturn-helix EF-hand $\mathrm{Ca}^{2+}$-sensing module followed by a sterile $\alpha$ motif (SAM) in the intraluminal $\mathrm{NH}_{2}$-terminal region. Decreased binding of $\mathrm{Ca}^{2+}$ to the EF hand has been shown to lead to the oligomerization of STIM1 followed by translocation of the multimers to membrane-adjacent ER areas where STIM1 can activate $\mathrm{Ca}^{2+}$ influx [9,11-13]. It has been reported that STIM1 expressed in the pulmonary arteries and played important roles in the activation of SOC in rat PASMCs [14]. However, The functions of STIM1 involved in HPH are still obscure. In this study, we present in vivo and in vitro evidence showing that hypobaric upregulates the expression of STIM1 in rat distal intrapulmonary arteries which plays an important role in the hypoxia-induced PASMCs proliferation via SOC/ $\mathrm{Ca}^{2+} /$ NFAT pathway and may represent a novel therapeutic target for the prevention of hypoxia pulmonary hypertension.

\section{Materials and methods \\ Animals}

All of the protocols and surgical procedures were approved by the Institutional Animal Use Committee of the Third Military Medical University and were in accordance with the National Institutes of Health and the American Physiological Society guidelines. Adult male Wistar rats $(6-7$ weeks old, $220-250 \mathrm{~g})$ were placed for 21 days in a chamber that was depressurised to $380 \mathrm{mmHg}$ with a 12-hour light-dark cycle. Age-matched controls were maintained in normal room air. Each group consisted of 15 experimental animals. The methods that were used to isolate the rat lungs were similar to those previously reported [15]. In brief, prior to lung isolation, mean pulmonary arterial pressures were measured as previously described [16]. After euthanizing the rats, the thorax was immediately opened and the heart and lungs were removed. The hearts were dissected to remove the right ventricle (RV) free wall and the left ventricle plus septum $(\mathrm{LV}+\mathrm{S})$, and the weight ratio of $\mathrm{RV} /(\mathrm{LV}+\mathrm{S})$ was used as an index of RV hypertrophy. The distal intrapulmonary arteries were dissected from the lungs and frozen in liquid nitrogen for subsequent examination.

\section{Morphological preparation and examination}

The lungs was perfused with $4 \%$ paraformaldehyde (PFA), inflated by infusion of $4 \%$ PFA at a constant pressure of $25 \mathrm{~cm} \mathrm{H}_{2} \mathrm{O}$ through the cannula inserted in the trachea, fixed in $4 \%$ PFA overnight at $4{ }^{\circ} \mathrm{C}$ and then embedded in OCT, and subsequently cut into $10-\mu \mathrm{m}$-thick sections for hematoxylin and eosin staining. Following
H\&E staining, Images of individual pulmonary arteries were captured using a digital camera, mounted on a light microscope, and linked to a computer. the ratio of vessel wall area to total area (WA\%) and the ratio of pulmonary arteriole wall thickness to vascular external diameter (WT\%) were measured using the Image-Pro Plus 5.1 software.

\section{Quantitative real-time polymerase chain reaction (qRTPCR)}

Total RNA from the intrapulmonary arteries (isolated as mentioned above) was isolated using the RNA simple Total RNA Kit (Tiangen), according to the manufacturer's protocol. Then, the total RNA was reversetranscribed to cDNA using the PrimeScript ${ }^{\circledR}$ RT reagent kit (TAKARA). Real-time PCR was performed using the SYBR $^{\circledR}$ Premix Ex Taq ${ }^{\mathrm{TM}}$ II kit (TAKARA). The primer sequences for STIM1 were 5'-CGTCCGCAACATCCA CAAG-3' (forward) and 5'-CCATAGGTCCTCCACGCT-3' (reverse). The primer sequences for $\beta$-actin were $5^{\prime}$-ACG GTCAGGTCATCACTATC-3' (forward) and 5'-TGCCA CAGGATTCCATACC-3' (reverse). The amplification conditions consisted of 1 cycle at $95^{\circ} \mathrm{C}$ for $30 \mathrm{~s}$ and 40 cycles of $95^{\circ} \mathrm{C}$ for $5 \mathrm{~s}, 60^{\circ} \mathrm{C}$ for $20 \mathrm{~s}$, and $72^{\circ} \mathrm{C}$ for $15 \mathrm{~s}$. Melting curve analyses were performed at conditions of $95^{\circ} \mathrm{C}$ for $1 \mathrm{~min}$ and then $55^{\circ} \mathrm{C}$ for $1 \mathrm{~min}$, which were followed by 80 increments of $+0.2^{\circ} \mathrm{C}$ at 10 -s intervals. The relative concentrations of each transcript were calculated using the standard curve method.

\section{Double-immunofluorescence staining}

The isolated lungs were formaldehyde fixed (4\% in PBS), cryoprotected with $30 \%$ sucrose in PBS, embedded in OCT media, and then frozen. Cryostat sections $(10 \mu \mathrm{m})$ were permeabilised and blocked for nonspecific binding and then incubated in $0.2 \%$ gelatin in PBS with the following primary antibodies at $4^{\circ} \mathrm{C}$ overnight: mouse monoclonal anti-STIM1 (1:100) (BD Bioscience) and rabbit polyclonal anti- $\alpha$-smooth muscle actin (1:250) (ABcam). The secondary antibodies [anti-mouse Cy3 and anti-rabbit FITC (1:500) (Biyuntian, China)] were prepared in $0.2 \%$ gelatin in PBS and were applied to the sections for $1 \mathrm{~h}$ at $37^{\circ} \mathrm{C}$. Nuclei were stained using DAPI (1:1,000 in PBS; Biyuntian, China). Images were taken using a confocal laser scanning microscope (Leica TCS SP5, Germany).

\section{Isolation and culture of PASMCs}

For isolation of the PASMCs, the adventitia of freshly excised distal (>4th generation) intrapulmonary arteries from adult male Wistar rats were removed. Vascular segments were then cut open, and the endothelium was removed by gently scraping the luminal surface of the vessel. Rat PASMCs were cultured as previously 
described [17]. In brief, the arteries were allowed to recover for $30 \mathrm{~min}$ in cold $\left(4^{\circ} \mathrm{C}\right)$ physiological salt solution (PSS) that contained $130 \mathrm{mM} \mathrm{NaCl}, 5 \mathrm{mM} \mathrm{KCl}, 1.2 \mathrm{mM}$ $\mathrm{MgCl}_{2}, 10 \mathrm{mM}$ HEPES, and $10 \mathrm{mM}$ glucose. This was followed by $20 \mathrm{~min}$ in reduced-Ca ${ }^{2+}$ PSS $\left(20 \mu \mathrm{M} \mathrm{CaCl}_{2}\right)$ at room temperature. The tissue was then digested at $37^{\circ} \mathrm{C}$ for $20 \mathrm{~min}$ in reduced-Ca ${ }^{2+}$ PSS containing collagenase (type $\mathrm{I}, 1,750 \mathrm{U} / \mathrm{ml})$, papain $(9.5 \mathrm{U} / \mathrm{ml})$, bovine serum albumin $(2 \mathrm{mg} / \mathrm{ml})$, and dithiothreitol $(1 \mathrm{mM})$. Cells were grown in DMEM supplemented with 10\% FBS and were passaged at a 1:3 ratio with trypsin treatment. The purity of the PASMCs in the primary cultures was confirmed using the specific mAb against smooth muscle $\alpha$-actin. Cells that had been passaged 3 to 8 times and were at $80 \%$ confluence were used for all experiments.

\section{RNA interference}

Small interfering RNA (siRNA) targeting STIM1 (siSTIM1) were designed as previously described [18] and synthesised by Genepharma. Scrambled (nonsense) siRNA (Genepharma) was used as negative control siRNA. Cells were transfected with siSTIM1 or Scrambled siRNA (final concentration of siRNA was $90 \mathrm{nM}$ ) (Invitrogen, Carlsbad, CA) using Lipofectamine RNAiMAX (Invitrogen) according to the manufacturer's instructions. After $24 \mathrm{~h}$, Cell growth was arrested by replacing medium with serum-free DMEM for $24 \mathrm{~h}$ under normoxic conditions. Growth-arrested cells were further incubated under either normoxic $\left(21 \% \mathrm{O}_{2}\right)$ or hypoxic conditions $\left(3 \% \mathrm{O}_{2}\right)$ for $24 \mathrm{~h}$.

\section{Western blotting}

Forty-eight hours after transfection, cells were collected for protein isolation. The cultured cells were washed twice with ice-cold PBS and lysed on ice in RIPA lysis buffer containing freshly added protease and phosphatase inhibitor cocktails. After $15 \mathrm{~min}$ of incubation, the cell lysate was collected by centrifuging the cells for $5 \min (16,000 \times \mathrm{g})$ at $4^{\circ} \mathrm{C}$. For nuclear and cytoplasmic fractions, adherent cells were washed in PBS, and the cytoplasmfraction was prepared by the addition of buffer C (10 mM Tris, pH 7.6, $10 \mathrm{mM} \mathrm{KCl,} 1.5 \mathrm{mM} \mathrm{MgCl}, 1 \%$ (v/v) Triton X-100, $1 \mathrm{mM}$ dithiothreitol, $0.2 \mathrm{mM} \mathrm{Na}_{3} \mathrm{VO}_{4}$, $0.4 \mathrm{mM}$ phenyl-methylsulfonyl fluoride, $10 \mu \mathrm{g} / \mathrm{ml}$ leupeptin, and $0.2 \mathrm{mM} \mathrm{NaF})$. After a 15 -min incubation on ice, lysates were spun for $5 \mathrm{~min}(10,000 \times \mathrm{g})$ at $4^{\circ} \mathrm{C}$. Supernatant containing the cytoplasm fraction was saved, and the pellet, containing the nuclear fraction, was washed once with buffer $C$ and resuspended in buffer N $(20 \mathrm{mM}$ Tris, pH 7.6, $160 \mathrm{mM} \mathrm{KCl}, 1.5 \mathrm{mM} \mathrm{MgCl}, 10 \%(\mathrm{v} / \mathrm{v})$ glycerol, $1 \mathrm{mM}$ dithiothreitol, $0.2 \mathrm{mM} \mathrm{Na}_{3} \mathrm{VO}_{4}, 0.4 \mathrm{mM}$ phenylmethylsulfonyl fluoride, $10 \mu \mathrm{g} / \mathrm{ml}$ leupeptin, and $0.2 \mathrm{mM} \mathrm{NaF}$ ). Nuclear lysates were incubated for $30 \mathrm{~min}$ on a rotating platformat $4{ }^{\circ} \mathrm{C}$ and spun $(16,000 \times \mathrm{g})$ for
$15 \mathrm{~min}$ at $4^{\circ} \mathrm{C}$. The amount of total protein was determined using a BCA protein assay kit (Pierce, Rockford, IL, USA). An equal amount of total protein (30-50 $\mu \mathrm{g})$ was loaded and separated by SDS-PAGE. The protein was transferred to polyvinylidene difluoride membranes and was then blocked and probed with the appropriate antibodies. Monoclonal Abs against STIM1 (BD Bioscience), Lamin B1 (Santa Cruz) and $\beta$-actin (Santa Cruz) or a polyclonal antibody against NFATc3 (Santa Cruz) were used as primary Abs. The membranes were then washed for 15 min 3 times and incubated with horseradish peroxidaseconjugated goat anti-rabbit or anti-mouse IgG for $1 \mathrm{~h}$. Bound antibodies were detected using an enhanced chemiluminescence system following the manufacturer's instructions. Densitometric signals were quantified by Quantity One software.

\section{Determination of cell proliferation}

PASMC proliferation was quantified by [3H]-thymidine incorporation, as described previously [19]. Briefly, $1 \mu \mathrm{Ci} /$ well [3H]-thymidine was added for the final 6 hours of cell culture, after which the cells were removed from the wells with trypsin digestion. The incorporated $[3 \mathrm{H}]$-thymidine was precipitated with $10 \%$ trichloroacetic acid and counted using a liquid scintillation counter. The experiments were repeated three times and results from five wells per experiment were determined and expressed as the average of the counts.

\section{Cell cycle and DNA analyses}

PASMCs were harvested by trypsin-EDTA treatment and were fixed in $70 \%$ ethanol. The ethanol was removed, and the cells were incubated in PBS containing RNase at $37^{\circ} \mathrm{C}$ for $30 \mathrm{~min}$. Next, the cells were stained with propidium iodide $(50 \mu \mathrm{g} / \mathrm{ml})$ and suspended in PBS for $30 \mathrm{~min}$ on ice. DNA fluorescence was measured by flow cytometry using an EPICS XL cytometer (Beckman Coulter, CA).

\section{Measurement of SOCE}

The $\left[\mathrm{Ca}^{2+}\right] \mathrm{i}$ in PASMCs was measured using the $\mathrm{Ca}^{2+}$-sensitive fluorescent indicator fluo-4/AM. Cells were loaded with fluo- 4 at $37^{\circ} \mathrm{C}$ for $30 \mathrm{~min}$ using a $\mathrm{Ca}^{2+}$-free physiological salt solution (D-HANKS) containing $5 \mu \mathrm{M}$ fluo-4/AM. The fluo-4-loaded cells were then perfused with a $\mathrm{Ca}^{2+}$-free physiological salt solution containing the following components: $0.5 \mathrm{mM}$ EGTA (Sigma Chemical, St Louis, MO)to chelate residual $\mathrm{Ca}^{2+}, 5 \mu \mathrm{M}$ nifedipine (Sigma Chemical, St Louis, MO) to prevent calcium entry through L-type voltage-operated $\mathrm{Ca}^{2+}$ channels (VOCC), and $10 \mu \mathrm{M}$ cyclopiazonic acid (CPA; Sigma Chemical) to deplete SR $\mathrm{Ca}^{2+}$ stores. The $\left[\mathrm{Ca}^{2+}\right]$ i was determined before and after the restoration of extracellular $\left[\mathrm{Ca}^{2+}\right]$ to $2.5 \mathrm{mM}$. SOCE was evaluated by measuring the peak increase in 
$\left[\mathrm{Ca}^{2+}\right]$ i caused by the restoration of extracellular $\mathrm{Ca}^{2+}$ in the continued presence of nifedipine and CPA.

\section{Immunofluorescence microscopy}

Cells were fixed for $30 \mathrm{~min}$ at room temperature with $4 \%$ formaldehyde in Dulbecco's phosphate-buffered saline (DPBS). Next, the cells were incubated with $0.2 \%$ Triton X-100 in DPBS for $15 \mathrm{~min}$ at room temperature. The cells were blocked with blocking solution (10\% goat serum in DPBS) for $1 \mathrm{~h}$ and then incubated with the primary antibodies (NFATc3, sc-8321, Santa Cruz Biotechnology, Santa Cruz, CA, USA) for $1 \mathrm{~h}$ at room temperature followed by the fluorescent-conjugated secondary antibody (FITC-conjugated AffiniPure goat anti-rabbit IgG, Beijing Zhongshan Golden Bridge Biological Technology Company, Beijing, China) for $90 \mathrm{~min}$ at room temperature. Nuclear staining was performed using DAPI (Biyuntian, China). The fluorescence was examined using a Leica laser scanning confocal microscope (Leica TCS SP5, Germany).

\section{Statistical methods}

Numerical data were expressed as the means \pm SEM. The SPSS10.0 software was used for the statistical analysis. An ANOVA was used with Scheffe's multiple comparison tests for multiple groups and student's $t$-test was used for two groups. P values $<0.05$ were regarded as statistically significant.

\section{Results}

\section{Morphological characteristics and alterations}

The mean pulmonary arterial pressures were $18.5 \pm$ $2.3 \mathrm{mmHg}$ and $31.5 \pm 3.7 \mathrm{mmHg}$ for the controls and the animals exposed to hypoxic conditions for 21 days, respectively $(\mathrm{p}<0.05, \mathrm{n}=10)$. Furthermore, the ventricular weight measurements revealed the $\mathrm{RV} /(\mathrm{LV}+\mathrm{S})$ ratios to be $0.26 \pm 0.02$ for control rats and $0.42 \pm 0.03$ for rats exposed to hypoxia for 21 days $(\mathrm{p}<0.05, \mathrm{n}=10)$. The histological H\&E staining demonstrated that the ratio of pulmonary arteriole wall thickness to vascular external diameter (WT\%) were $16.2 \pm 5.2$ and $34.8 \pm 7.4$ for the control and rats exposed to hypoxia for 21 days respectively $(\mathrm{p}<0.05, \mathrm{n}=3)$. The ratio of vessel wall area to total area (WA\%) were $29.7 \pm 7.9$ and $56.2 \pm 8.8$ for the control and rats exposed to hypoxia for 21 days respectively $(\mathrm{p}<0.05, \mathrm{n}=3)$. These data indicated that the wall area and wall thickness percentages were significantly increased in the hypoxia-treated group compared to the control group (Figure 1).

\section{Effects of hypoxia on the expression of STIM1 in rat distal} intrapulmonary arteries

To detect the effects that hypoxia had on the expression of STIM1 in rat distal intrapulmonary arteries, real-time
RT-PCR and western blotting were done with total RNA and cytosolic protein extracts from rat distal intrapulmonary arteries. Localization of STIM1 and SM $\alpha$ Apositive cells in rat small pulmonary arteries was done by double-immunofluorescence staining to determine the spatial distribution and cellular localization. Compared with the control groups, the expression of STIM1 mRNA and protein increased significantly in the distal intrapulmonary of animals in the 21-day hypoxia treatment group (Figure 2).

\section{Silencing of STIM1 significantly inhibites PASMCs proliferation under hypoxia}

STIM1 protein expression in PASMCs of siNT group was not significantly different compared with the untreated group. In contrast, siSTIM1 treatment significantly reduced STIM1 protein expression, as compared to siNT treatment or no treatment $(\mathrm{P}<0.01)$ (Figure $3 \mathrm{~A}$ and $\mathrm{B}$ ). Next, we investigated the effect of the STIM1 siRNA treatment on PASMCs proliferation under hypoxic conditions. After 24 hours of $3 \%$ oxygen treatment, there was a significant increase in PASMCs proliferation, as measured by [3H]thymidine (3H-TdR) incorporation. Meanwhile, Silencing of STIM1 significantly inhibited hypoxia induced PASMCs proliferation. In addition, there were no significant differences between siNT-treated group and control group (Figure 3C).

\section{Silencing of STIM1 significantly reduces the cell cycle progression of PASMCs under hypoxia}

As PASMCs proliferation was significantly inhibited by STIM1 siRNA treatment, we investigated whether this inhibition could be due to an alteration in cell cycle progression. Flow cytometry was performed to analyse the phases of the cell cycle for each group. We found that treatment with $3 \% \mathrm{O}_{2}$ significantly increased PASMCs cell cycle progression, while Silencing of STIM1 significantly inhibited cell cycle progression under hypoxic conditions (Figure 3D).

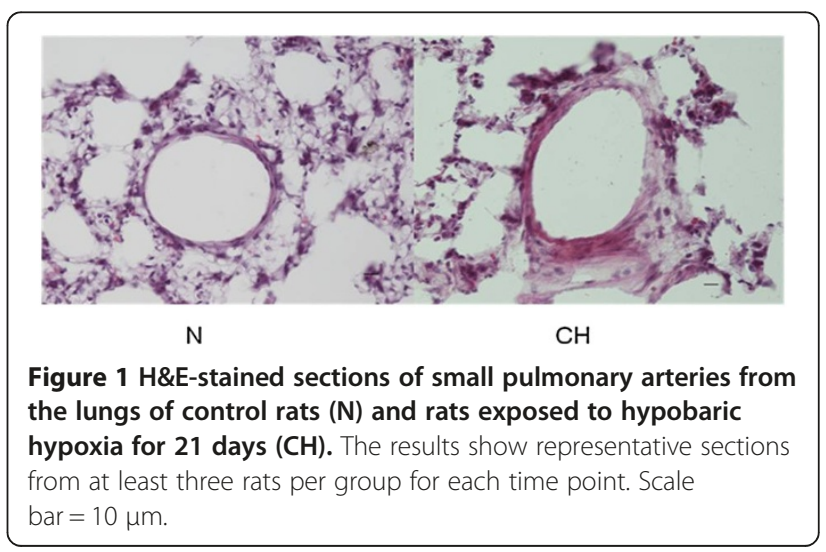



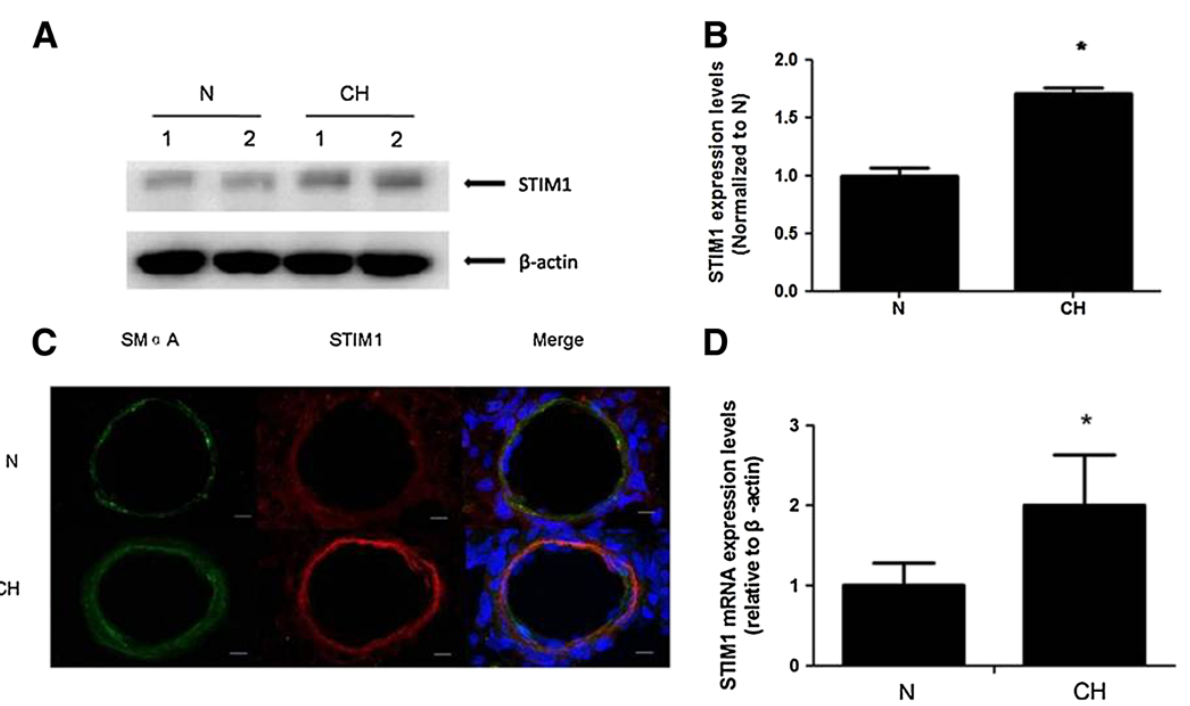

Figure 2 The effects of chronic hypoxia on STIM1 mRNA and protein expression. Representative Western blot images (A) and summarized data (B) for STIM1 proteins in distal (>4th generation) intrapulmonary arteries from control rats $(\mathrm{N})$ and rats exposed to hypobaric hypoxia for 21 days (CH). $\beta$-actin was used as a loading control. Graph shows protein expression of STIM1 normalized to an average level in N. The results are expressed as the mean \pm SEM for five experiments *: $P<0.05$ compared to the $N$ group. (C) STIM1 (red) and a-smooth muscle actin (ACTA2) (green) immunofluorescence staining in small pulmonary arteries from $\mathrm{N}$ and $\mathrm{CH}$. Nuclei are counterstained with DAPI (blue). Scale bar $=10 \mu \mathrm{m}$. The results shown are from a single experiment and are representative of three separate experiments. (D) Analysis of STIM1 mRNA expression in distal (>4th generation) intrapulmonary arteries from $N$ and $\mathrm{CH}$. Parallel amplification of the rat housekeeping $\beta$-actin gene was used as an internal control. The results are expressed as the mean \pm SEM for five experiments. *: $P<0.05$ compared to the $N$ group.

\section{Silencing of STIM1 inhibits hypoxia-induced enhancement of $\mathrm{SOC} /\left[\mathrm{Ca}^{2+}\right]$ i in PASMCs}

As hypoxia-induced PASMCs proliferation is typically associated with extracellular $\mathrm{Ca}^{2+}$ influx through SOC, we investigated whether the anti-proliferative effects of STIM1 silencing were related to changes in $\mathrm{SOC} /\left[\mathrm{Ca}^{2+}\right] \mathrm{i}$ as a result of hypoxia. Hypoxia was found to induce a significant increase in peak $\left[\mathrm{Ca}^{2+}\right]$ i levels $(\mathrm{P}<0.05)$ in PASMCs compared to cells from normoxic conditions. The silencing of STIM1 markedly inhibited the hypoxiainduced increase in SOC-mediated $\mathrm{Ca}^{2+}$ influx $(\mathrm{P}<0.05)$. These results suggest that STIM1 silencing may exert its anti-proliferative effect by inhibiting the activation of the $\mathrm{SOC} /\left[\mathrm{Ca}^{2+}\right]$ i pathway under hypoxic conditions (Figure 4).

\section{Silencing of STIM1 inhibits hypoxia-induced NFATC3 nuclear translocation}

In normoxic-treated PASMCs, NFATc3 immunostaining in the nucleus was weak which suggested that NFATc3 levels in the nucleus were low and that there was a lack of significant nuclear translocation. Hypoxia treatment significantly stimulated the nuclear translocation of NFATc3, which was indicated by strong NFATc3 staining in the nucleus. Moreover, the silencing of STIM1 significantly attenuated the nuclear translocation of NFATc3 induced by hypoxia (Figure 5A). That silencing of STIM1 inhibits hypoxiainduced NFATc3 nuclear translocation was confirmed by western blot analysis of nuclear extracts(Figure 5B).

\section{Discussion}

Continuous or intermittent hypobaric hypoxia can lead to long-term contraction of the pulmonary artery and structural changes in the pulmonary vascular wall known as hypoxic pulmonary vessel remodelling (HPVR) [20]. HPVR is characterised by thickening of small pulmonary artery wall and muscularizing of pulmonary arteriole, which can result in sustained high pulmonary artery pressure and right ventricular hypertrophy [21]. It has become clear that pulmonary vascular smooth muscle cells (PASMCs) are closely related to the development of pulmonary hypertension, which are regulated by intracellular $\mathrm{Ca}^{2+}$ concentrations and calmodulin (CaM) [1]. The intracellular $\mathrm{Ca}^{2+}$ concentration has also been suggested to regulate gene expression and cellular proliferation [2,6,22-25]. Intracellular calcium levels in PASMCs are mainly regulated by extracellular calcium influx and the release of intracellular calcium stores. Chelation of extracellular calcium in human PASMCs can significantly inhibit serum or growth-factor induced cell proliferation. The intracellular levels of calcium were significantly higher in proliferating PASMCs than resting PASMCs [26]. These results suggested that a continuous inflow of extracellular calcium is necessary for cell proliferation. The calcium channels found at the plasma membrane, which mediate the influx of extracellular calcium, include voltagedependent calcium channels (VDCC), receptor-operated calcium channels (ROC), and store-operated calcium 

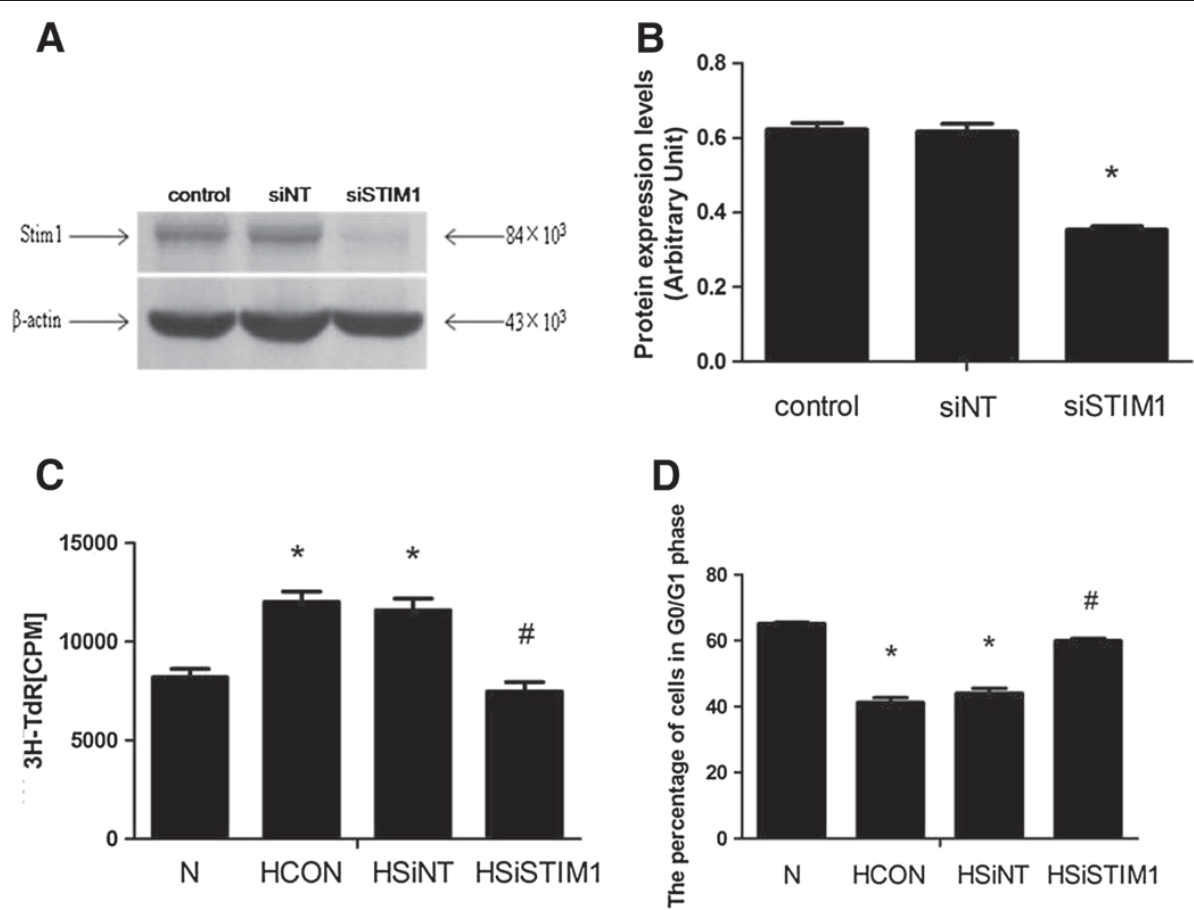

Figure 3 The effect of STIM1 silencing on rat PASMC proliferation and cell cycle progression under hypoxia. (A). Western blot showing STIM1 and $\beta$-actin protein expression from untreated control PASMCs (Control) and PASMCs treated with transfection-nontargeted siRNA (siNT) or siRNA targeted to STIM1 (siSTIM1). (B). Mean ratios of STIM1 protein expression relative to that of $\beta$-actin, as measured by Western blotting in Control, siNT, and siSTIM1 PASMCs. *: $P<0.05$ compared to the Control group and the siNT group. The results are expressed as the mean \pm SEM of four experiments. (C)After transfection with STIM1 siRNA, PASMCs were cultured in hypoxic conditions for 24 hours. [3H]-thymidine (3H-TdR) incorporation was measured to detect PASMC proliferation. (D) PASMCs were harvested for flow cytometry-based cell cycle analysis. PASMCs were either left untreated under normoxic conditions $(\mathrm{N})$, left untreated under hypoxic conditions (HCON), treated with nontargeted siRNA under hypoxic conditions (HsiNT), or treated with siRNA targeted to STIM1 under hypoxic conditions (HsiSTIM1). *:P $<0.05$ compared with the Control group and \#:P<0.05 compared with the HCON and HsiNT group. The results are expressed as the mean \pm SEM of three experiments.

channels (SOC). VDCCs are regulated by membrane potential, while SOCs are activated by the depletion of intracellular calcium stores. ROCs can activate G proteins and phospholipase C (PLC), which then hydrolyse phosphatidylinositol 4,5 bisphosphate (PIP2) to generate 1, 4, 5 - trisphosphate (IP3) and diacylglycerol (DAG). IP3 acts on the endoplasmic reticulum (ER) or the sarcoplasmic reticulum (SR) to cause $\mathrm{Ca}^{2+}$ to be released from calcium stores and to activate SOC $[7,8]$. Previous studies have suggested that hypoxia can suppress voltage-dependent potassium channels $(\mathrm{Kv})$ and cause cell membrane depolarisation and the activation of VDCCs. Increased concentrations of intracellular calcium ions can lead to pulmonary vasoconstriction and vascular remodelling [2-5]. However, recent evidence has also indicated that SOCs also play a very important role in the pathogenesis of hypoxic pulmonary hypertension. Vera et al have reported that $\mathrm{Ni}^{2+}$ known as SOC blocker can significantly inhibit the proliferation of cultured PASMCs [27,28]. Meanwhile, Lin et al showed that PASMC SOCs are upregulated by chronic hypoxia and contribute to the enhanced vascular tone in hypoxic pulmonary hypertension [6].

The molecular composition and the mechanisms behind the activation of SOCs remained enigmatic for almost 20 years $[28,29]$. Then, in 2005, using an RNA interference-based high-throughput screen in Drosophila S2 cells with 170 genes, Roos et al. [9] identified the gene for STIM1 as being required for thapsigargininduced SOC entry. In addition, SOC were not activated in human T cells and HEK293 cells upon the depletion of intracellular calcium stores when STIM1 was silenced. Liou et al. [10] also used an RNA interference-based high-throughput screen in Hela cells with 2,304 genes to identify STIM1 as the key factor necessary to activate SOCs. These experiments indicated that STIM1 was a SOC-specific gene that regulated SOC activity, and the results of these studies indicated that STIM1 may be a novel target for SOC-related diseases. Recently, Lu et al. [14] reported that expression of STIM1 was greater in distal than proximal PASMCs, which may account for the reason why HPV is greater in distal than proximal 

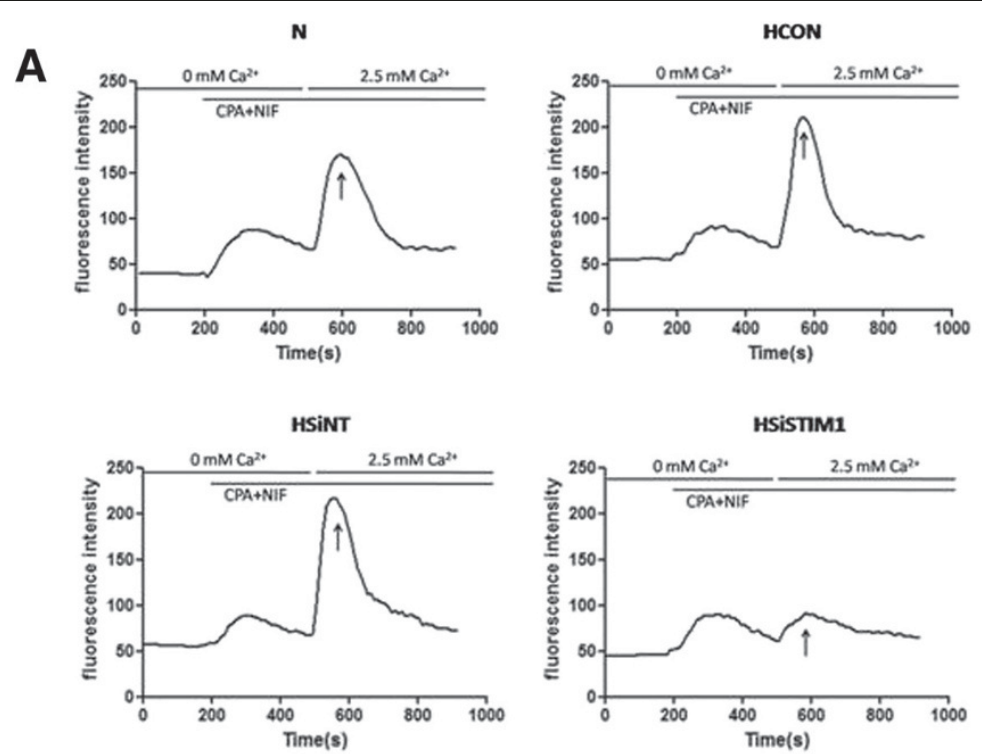

\section{B Maximum Response to $\mathbf{C a}^{2+}$ Restoration}

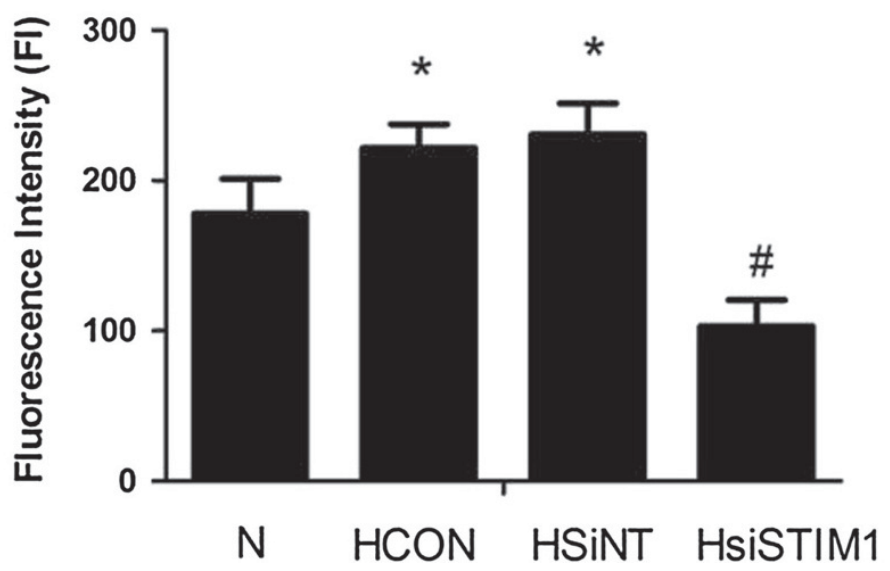

Figure 4 The effect of STIM1 silencing on hypoxia-induced enhancement of SOC-mediated $\mathrm{Ca}^{2+}$ influx. After transfection with STIM1 siRNA, PASMCs were cultured in hypoxic conditions for 24 hours. The SOC-mediated PASMC Ca ${ }^{2+}$ influx was measured following stimulation with $10 \mu \mathrm{M}$ cyclopiazonic acid during the change from $\mathrm{Ca}^{2+}$-free conditions to $2.5 \mathrm{mM} \mathrm{Ca}^{2+}$. PASMCs were either left untreated under normoxic conditions $(\mathrm{N})$, left untreated under hypoxic conditions ( $\mathrm{HCON})$, treated with nontargeted siRNA under hypoxic conditions (HsiNT), or treated with siRNA targeted to STIM1 under hypoxic conditions (HsiSTIM1). A: Representative raw trace illustrating the changes in $\left[\mathrm{Ca}^{2+}\right]$ i (presented as fluorescence intensity (FI) in PASMCs in different groups. B: Summary of the data illustrated in showing averaged changes in fluorescence after $2.5 \mathrm{mM} \mathrm{Ca}^{2+}$ restoration. *:P $<0.05$ compared with the Control group and \#:P<0.05 compared with the HCON and HsiNT group. The results are expressed as the mean \pm SEM of three separate experiments.

pulmonary arteries. However, the role of STIM1 in the development of chronic hypoxic pulmonary hypertension especially the relationship between hypoxia induced PASMCs proliferation and STIM1 remains obscure. Therefore, we investigated STIM1 expression level in the distal intrapulmonary vasculature of normal rats and animals exposed to chronic hypoxia. The results demonstrated that a significant upregulation of STIM1 expression was associated with chronic hypoxia-induced PASMC hyperproliferation in the distal intrapulmonary vasculature. Our data indicate that STIM1 protein may be involved in the regulation of hypoxic pulmonary vascular remodelling.

In addition, we used STIM1-specific siRNA to silence the STIM1 expression in rat PASMCs under conditions of hypoxia to investigate the role of STIM1 in the regulation of hypoxia-induced PASMC proliferation. We found that the knockdown of STIM1 expression in PASMCs by RNA interference was highly specific and could be quantitated at the protein level. STIM1 knockdown markedly inhibited 


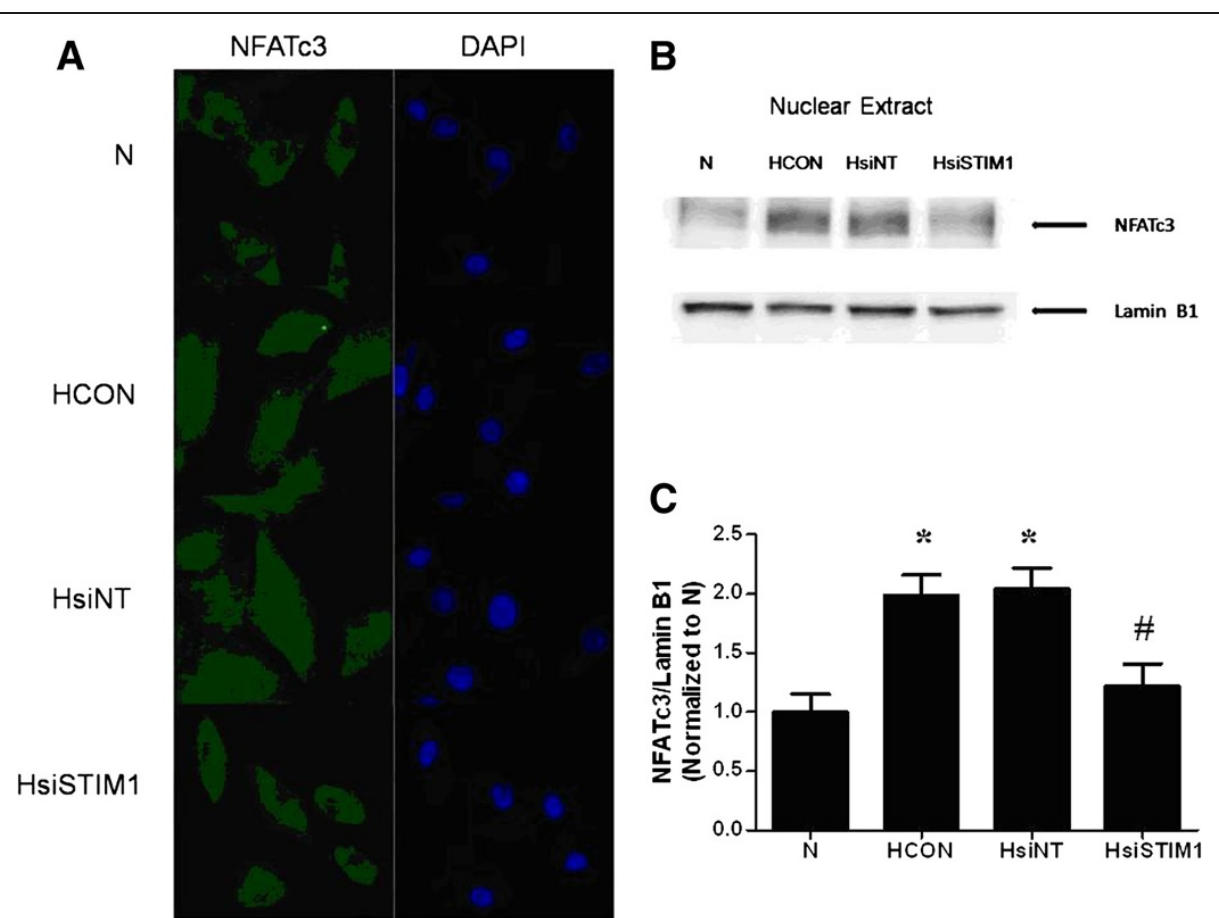

Figure 5 The effect of STIM1 silencing on hypoxia-induced nuclear translocation of NFATc3 in PASMCs. NFATC3 staining was visualised by confocal microscopy and immunofluorescence. The primary antibody against NFATc3 was detected using a FITC-conjugated AffiniPure goat anti-rabbit IgG secondary antibody (green). The slides were counterstained with the nuclear dye DAPI (blue). (A): Immunofluorescence image of NFATC3 in PASMCs: PASMCs were either left untreated under normoxic conditions (N), left untreated under hypoxic conditions (HCON), treated with nontargeted siRNA under hypoxic conditions (HsiNT), or treated with siRNA targeted to STIM1 under hypoxic conditions (HsiSTIM1). Representative Western blot images (B) and summarized data (C) for NFATc3 nuclear levels, Lamin B1 was used as a loading control. *:P<0.05 compared with the Control group and \#:P<0.05 compared with the HCON and HsiNT group. The results are expressed as the mean \pm SEM of three separate experiments.

SOCE, as measured by the peak $\left[\mathrm{Ca}^{2+}\right] \mathrm{i}$ response to the restoration of extracellular $\mathrm{Ca}^{2+}$. These findings are consistent with those of other smooth muscles [30,31], including the murine aorta, the human airway, the coronary artery, and the saphenous vein, and confirm that STIM1 contributes significantly to SOCE in pulmonary smooth muscle. Moreover, STIM1 silencing not only inhibited PASMCs proliferation but also reduced the cell cycle progression induced by hypoxia. These results demonstrate that STIM1 is a critical regulator of hypoxia-induced PASMCs proliferation.

Nuclear factor of activated $\mathrm{T}$ cells (NFAT) is a $\mathrm{Ca}^{2+}$-dependent transcription factor. Elevated levels of intracellular $\mathrm{Ca}^{2+}$ increase the activity of the $\mathrm{Ca}^{2+}$ calmodulin-dependent phosphatase calcineurin. Activated calcineurin dephosphorylates multiple serine residues within the regulatory region of the NFAT molecule to induce a conformational change in NFAT that exposes nuclear localisation signals and allows for NFAT nuclear import and the subsequent regulation of gene transcription [32]. The NFAT transcription factor family is composed of four well-characterised members including NFATc1 (NFAT2/c), NFATc2 (NFAT1/p), NFATc3
(NFAT4/x), and NFATc4 (NFAT3) [33]. The NFATc3 isoform has specifically been implicated in vasculature development, the maintenance of a contractile phenotype, and the regulation of vascular smooth muscle cell (VSMC) contractility. Recently, Sergio et al. [34] reported that chronic hypoxia induced NFAT transcriptional activity and NFATc3 nuclear translocation in mouse pulmonary arteries. Wang et al. [35] reported that hypoxia-induced NFAT nuclear translocation via the up-regulation of TRPC1 as well as increased SOC-mediated $\mathrm{Ca}^{2+}$ influx and the inhibition of the SOC/Ca ${ }^{2+} / \mathrm{NFAT}$ pathway was involved in the anti-proliferative effect of sildenafil on PASMCs. These results highlight the important role that the SOC/ $\mathrm{Ca}^{2+} / \mathrm{NFATc} 3$ pathway plays during the development of hypoxic pulmonary hypertension. In this study, we hypothesised that STIM1 knockdown would inhibit the proliferation of PASMCs under hypoxia via the inhibition of the SOC/Ca ${ }^{2+/}$ NFATc3 pathway. By observing the effect of STIM1 knockdown on PASMC SOC-mediated $\mathrm{Ca}^{2+}$ influx and NFATc3 nuclear translocation under hypoxic conditions, we found that hypoxia could increase SOC-mediated $\mathrm{Ca}^{2+}$ influx and promote NFATc3 nuclear translocation. Thus, STIM1 silencing could significantly 
inhibit SOC-mediated $\mathrm{Ca}^{2+}$ influx and NFATc3 nuclear translocation. These results indicate that STIM1 is an essential regulator of the SOC/Ca ${ }^{2+} / \mathrm{NFAT}$ pathway, which plays an important role in hypoxia-induced PASMC proliferation.

In summary, this report presents in vivo and in vitro evidence to indicate that STIM1 may be involved in the development of hypoxic pulmonary vessel remodelling. As hypoxia induces PASMCs proliferation through a STIM1dependent mechanism and the $\mathrm{SOC} / \mathrm{Ca}^{2+} / \mathrm{NFAT}$ pathway, STIM1 may represent a novel therapeutic target for the prevention of hypoxic pulmonary hypertension.

\section{Competing interests}

The authors declare that they have no competing interests.

\section{Authors' contributions}

$\mathrm{XH}$ contributed in all the data experiments, analysis and elaborated the figures. JC performed the Western blot, their analysis and contributed to immunofluorescence experiments. YL contributed in QRT-PCR analysis and amelioration of the manuscript. FL and GX contributed in analyzed in vivo measurements and cell culture experiments. YG designed the study, supervised the overall study and wrote the manuscript. All authors have read and approved the manuscript.

\section{Acknowledgments}

This work was supported by the 973 Project of China (No. 2012CB518200) and the National Key Technology R \& D Program of China (No.2009BAl85B01)

\section{Author details}

'Department of Pathophysiology and high altitude physiology, College of high altitude military medicine, Third Military Medical University, Chongqing, China. ${ }^{2}$ Key Laboratory of High Altitude Medicine, Third Military Medical University, Ministry of Education, Chongqing 400038, China. ${ }^{3}$ Key Laboratory of High Altitude Medicine of PLA, Chongqing 400038, China.

Received: 1 March 2012 Accepted: 19 December 2012

Published: 5 January 2013

\section{References}

1. Yidiz P: Molecular mechanisms of pulmonary hypertension [J]. Clin Chim Acta 2009, 403(1-2):9-16

2. Wang J, Juhaszova M, Rubin LJ, et al: Hypoxia inhibits gene expression of voltage-gated $\mathrm{K}^{+}$channel alpha subunits in pulmonary artery smooth muscle cells [J]. J Clin Invest 1997, 100(9):2347-2353.

3. Platoshyn O, Yu Y, Golovina VA, et al: Chronic hypoxia decreases $K_{(V)}$ channel expression and function in pulmonary artery myocytes [J]. Am J Physiol Lung Cell Mol Physiol 2001, 280(4):L801-812.

4. Reeve HL, Michelakis E, Nelson DP, et al: Alterations in a redox oxygen sensing mechanism in chronic hypoxia [J]. J Appl Physiol 2001, 90(6):2249-2256.

5. Shimoda LA, Sylvester JT, Sham JS: Chronic hypoxia alters effects of endothelin and angiotensin on $\mathrm{K}^{+}$currents in pulmonary arterial myocytes [J]. Am J Physiol 1999, 277(3 Pt 1):L431-439.

6. Lin MJ, Leung GP, Zhang WM, et al: Chronic hypoxia-induced upregulation of store-operated and receptor-operated $\mathrm{Ca}^{2+}$ channels in pulmonary arterial smooth muscle cells: a novel mechanism of hypoxic pulmonary hypertension [J]. Circ Res 2004, 95(5):496-505.

7. Hofmann $T$, Obukhov AG, Schaefer M, et al: Direct activation of human TRPC6 and TRPC3 channels by diacylglycerol [J]. Nature 1999, 397(6716):259-263.

8. Trebak M, St JBG, McKay RR, et al: Signaling mechanism for receptoractivated canonical transient receptor potential 3 (TRPC3) channels [J]. J Biol Chem 2003, 278(18):16244-16252.
9. Roos J, DiGregorio PJ, Yeromin AV, et al: STIM1, an essential and conserved component of store-operated $\mathrm{Ca}^{2+}$ channel function [J]. J Cell Biol 2005, 169(3):435-445.

10. Liou J, Kim ML, Heo WD, et al: STIM is a $\mathrm{Ca}^{2+}$ sensor essential for $\mathrm{Ca}^{2+}$-store-depletion-triggered Ca ${ }^{2+}$ influx [J]. Curr Biol 2005, 15(13):1235-1241.

11. Liou J, Fivaz M, Inoue T, et al: Live-cell imaging reveals sequential oligomerization and local plasma membrane targeting of stromal interaction molecule 1 after $\mathrm{Ca}^{2+}$ store depletion [J]. Proc Natl Acad Sci USA 2007, 104(22):9301-9306.

12. Hewavitharana T, Deng X, Soboloff J, et al: Role of STIM and Orai proteins in the store-operated calcium signaling pathway [J]. Cell Calcium 2007, 42(2):173-182.

13. Manji SS, Parker NJ, Williams RT, et al: STIM1: a novel phosphoprotein located at the cell surface [J]. Biochim Biophys Acta 2000, 1481(1):147-155.

14. Lu W, Wang J, Shimoda LA, et al: Differences in STIM1 and TRPC expression in proximal and distal pulmonary arterial smooth muscle are associated with differences in $\mathrm{Ca}^{2+}$ responses to hypoxia [J]. Am J Physiol Lung Cell Mol Physiol 2008, 295(1):L104-113.

15. Klinger JR, Warburton RR, Pietras $L$, et al: Brain natriuretic peptide inhibits hypoxic pulmonary hypertension in rats [J]. J Appl Physiol 1998, 84(5):1646-1652

16. Yamamoto A, Takahashi H, Kojima Y, et al: Downregulation of angiopoietin-1 and Tie2 in chronic hypoxic pulmonary hypertension [J]. Respiration 2008, 75(3):328-338.

17. Wang J, Shimoda LA, Sylvester JT: Capacitative calcium entry and TRPC channel proteins are expressed in rat distal pulmonary arterial smooth muscle [J]. Am J Physiol Lung Cell Mol Physiol 2004, 286(4):L848-858

18. Aubart FC, Sassi $Y$, Coulombe A, et al: RNA interference targeting STIM1 suppresses vascular smooth muscle cell proliferation and neointima formation in the rat [J]. Mol Ther 2009, 17(3):455-462.

19. Morrell NW, Upton PD, Kotecha S, et al: Angiotensin II activates MAPK and stimulates growth of human pulmonary artery smooth muscle via AT1 receptors [J]. Am J Physiol 1999, 277(3 Pt 1):L440-448.

20. Stenmark KR, Fagan KA, Frid MG: Hypoxia-induced pulmonary vascular remodeling: cellular and molecular mechanisms [J]. Circ Res 2006, 99(7):675-691.

21. Uzunpinar A, Cilingiroglu M: Pulmonary arterial hypertension [J]. Curr Atheroscler Rep 2009, 11(2):139-145.

22. Weir EK, Archer SL: The mechanism of acute hypoxic pulmonary vasoconstriction: the tale of two channels [J]. FASEB J 1995, 9(2):183-189.

23. Li KX, Fouty B, McMurtry IF, et al: Enhanced ET(A)-receptor-mediated inhibition of $\mathrm{K}(\mathrm{v})$ channels in hypoxic hypertensive rat pulmonary artery myocytes [J]. Am J Physiol 1999, 277(1 Pt 2):H363-370.

24. Yuan JX, Aldinger AM, Juhaszova $M$, et al: Dysfunctional voltage-gated $\mathrm{K}^{+}$ channels in pulmonary artery smooth muscle cells of patients with primary pulmonary hypertension [J]. Circulation 1998, 98(14):1400-1406.

25. Yu Y, Fantozzi l, Remillard CV, et al: Enhanced expression of transient receptor potential channels in idiopathic pulmonary arterial hypertension [J]. Proc Natl Acad Sci USA 2004, 101(38):13861-13866.

26. Oka MMK, McMurtry IF: NIP-121 is more effective than nifedipine in acutely reversing chronic pulmonary hypertension. J Appl Physiol 1993, 75(3):1075-1080.

27. Golovina VA, Platoshyn O, Bailey $\mathrm{CL}$, et al: Upregulated TRP and enhanced capacitative $\mathrm{Ca}^{2+}$ entry in human pulmonary artery myocytes during proliferation [J]. Am J Physiol Heart Circ Physiol 2001, 280(2):H746-755.

28. Parekh AB, Putney JW Jr: Store-operated calcium channels [J]. Physiol Rev 2005, 85(2):757-810.

29. Smyth JT, Dehaven $\mathrm{Wl}$, Jones BF, et al: Emerging perspectives in store-operated $\mathrm{Ca}^{2+}$ entry: roles of Orai, Stim and TRP [J]. Biochim Biophys Acta 2006, 1763(11):1147-1160.

30. Peel SE, Liu B, Hall IP: A key role for STIM1 in store operated calcium channel activation in airway smooth muscle [J]. Respir Res 2006, 7(1):119.

31. Stiber J, Hawkins A, Zhang ZS, et al: STIM1 signalling controls storeoperated calcium entry required for development and contractile function in skeletal muscle [J]. Nat Cell Biol 2008, 10(6):688-697.

32. Hill-Eubanks DC, Gomez MF, Stevenson AS, et al: NFAT regulation in smooth muscle [J]. Trends Cardiovasc Med 2003, 13(2):56-62.

33. Rao A, Luo C, Hogan PG: Transcription factors of the NFAT family: regulation and function [J]. Annu Rev Immunol 1997, 15:707-747. 
34. de Frutos S, Spangler R, Alo D, et al: NFATc3 mediates chronic hypoxia-induced pulmonary arterial remodeling with alpha-actin up-regulation [J]. J Biol Chem 2007, 282(20):15081-15089.

35. Wang $\mathrm{C}$, Li JF, Zhao L, et al: Inhibition of SOC/Ca ${ }^{2+} / \mathrm{NFAT}$ pathway is involved in the anti-proliferative effect of sildenafil on pulmonary artery smooth muscle cells [J]. Respir Res 2009, 10(123):123.

doi:10.1186/1465-9921-14-2

Cite this article as: Hou et al: Silencing of STIM1 attenuates hypoxiainduced PASMCs proliferation via inhibition of the SOC/Ca ${ }^{2+} / \mathrm{NFAT}$ pathway. Respiratory Research 2013 14:2.

\section{Submit your next manuscript to BioMed Central and take full advantage of:}

- Convenient online submission

- Thorough peer review

- No space constraints or color figure charges

- Immediate publication on acceptance

- Inclusion in PubMed, CAS, Scopus and Google Scholar

- Research which is freely available for redistribution 